\title{
Article \\ Relationship between Active Aging and Quality of Life in Middle-Aged and Older Koreans: Analysis of the 2013-2018 KNHANES
}

\author{
MiJung Eum ${ }^{1}$ and HyungSeon Kim ${ }^{2, *(D)}$ \\ 1 Department of Nursing Science, Kyungbuk College, 77 Daehak-ro, Yeongju-si 36133, Gyeongbuk, Korea; \\ emj44@hanmail.net \\ 2 Department of Nursing, Bucheon University, 56 Sosa-ro, Bucheon-si 14774, Gyeonggi-do, Korea \\ * Correspondence: esther0701@bc.ac.kr; Tel.: +82-326-108-302
}

check for updates

Citation: Eum, M.; Kim, H.

Relationship between Active Aging and Quality of Life in Middle-Aged and Older Koreans: Analysis of the 2013-2018 KNHANES. Healthcare 2021, 9, 240. https://doi.org/ $10.3390 /$ healthcare 9020240

Academic Editor: Hideki Nakano

Received: 2 February 2021

Accepted: 19 February 2021

Published: 23 February 2021

Publisher's Note: MDPI stays neutral with regard to jurisdictional claims in published maps and institutional affiliations.

Copyright: (c) 2021 by the authors. Licensee MDPI, Basel, Switzerland. This article is an open access article distributed under the terms and conditions of the Creative Commons Attribution (CC BY) license (https:// creativecommons.org/licenses/by/ $4.0 /)$.

\begin{abstract}
With the increase in the aging population worldwide, social interest in having a vibrant and valuable old age has been increasing with changes in the perspectives on old age. This study aimed to determine the relationship between active aging and health-related quality of life (HRQOL) in middle-aged and older Korean using national data. The subjects were 14,117 adults aged $\geq 55$ years. HRQOL was evaluated using the EuroQol-5 Dimension (EQ-5D) questionnaire, and active aging was defined based on the health factors, participation factors, and security factors. The average EQ-5D score was $91.04 \pm 0.143$. Hierarchical multiple regression analysis sequentially inputting the health, participation, and security factors showed that health factors had the strongest influence on HRQOL ( $F=216.656, p<0.001)$. In the final model, which included all variables, activity limit $(\mathrm{B}=-10.477, p<0.001)$ and subjective health status $(\mathrm{B}=-7.282, p<0.001)$ were closely related to the HRQOL. In addition, economic activity, income level, home ownership, private health insurance, and unmet healthcare needs were associated with HRQOL. The $\mathrm{R}^{2}$ of the model was $38.2 \%$. To improve the HRQOL of middle-aged and older people, it is necessary to consider active aging factors. Furthermore, follow-up studies using various indicators reflecting active aging should be conducted.
\end{abstract}

Keywords: health-related quality of life; active aging; middle aged; aged

\section{Introduction}

According to the United Nations Population Fund, the world population is aging rapidly, with people aged $\geq 60$ years accounting for $12.3 \%$ of the world's population, and this number is projected to increase to nearly $22 \%$ by 2050 [1]. South Korea became an aged society in 2019 , with $14.9 \%$ of the population aged $\geq 65$ years, and the proportion is expected to increase to $46.5 \%$ by 2067 [2]. In particular, as Korea took only 18 years to enter the aged society due to a continuous decline in childbirth and prolonged life expectancy, Korea received attention as the country with the fastest pace of aging among the Organization for Economic Co-operation and Development (OECD) countries [3]. Therefore, compared with other developed countries that have prepared for an aging society, Korea faces various problems related to aging, such as economic difficulties experienced in old age, increasing physical and mental chronic diseases, death of a spouse, loss of role, and social isolation. All these situations made it necessary for Korea to prepare for the problems urgently [4].

As social interest in the valuable life of old age has increased due to longer life expectancy, negative perceptions about old age have changed and people of old age have been redefined as positive and active members of the society [5]. The concept of 'active aging' has been acknowledged by international organizations due to a new paradigm shift in aging populations [6]. The World Health Organization (WHO) defines active aging as the process of optimizing opportunities for health, participation, and security to enhance the quality of life as people age [7]. Attention should be focused on the factors related to 
the life of the aging population, because interest in improving the older adults' quality of life gradually increases in accordance with the national income, living standards, and the prevalence of chronic diseases; in particular, the quality of life of older adults is closely related to the quality of life at the national level.

The WHO suggested that health, participation, and security factors are components of active aging. They also indicated that these three factors are closely related to each other, health and security factors activate participation factors, and health and security factors can be enhanced by participation factors [7].

According to previous studies, the quality of life of older adults is affected by general characteristics such as age and education level [8,9] and lifestyle characteristics such as smoking, drinking, and sleep [10-12]. Moreover, quality of life is closely related to physical and mental status [13-15]; it is helpful for older adults to frequently engage in leisure activities to maintain quality of life [16], and the employment status of older adults has a greater relevance to quality of life compared with younger adults $[17,18]$.

Active aging has a positive effect on the quality of life [19], and is understood in relation to physical, cognitive, psychological and social factors, but these co-exist in complex combinations [20]. Although there is a significant relationship between active aging and quality of life, most countries do not offer the generalized conditions of a proper life quality for their older population [21]. Hence, a strategy to provide these conditions should be established. Although interest in investigating the components of active aging has gradually increased in recent years with the increase in the older population, there is insufficient evidence showing the sub-factors that constitute active aging; studies tend to focus mainly on the aging population in Western countries, and selectively apply or analyze those parts that constitute active aging. In addition, studies evaluating the relationship between active aging and quality of life are limited in quantity.

Therefore, this study aimed to define the components of active aging and identify the level of health-related quality of life (HRQOL) using a large national sample of people aged $\geq 55$ years from the 2013-2018 Korean National Health and Nutrition Examination Survey (KNHANES). We also aimed to identify active aging factors that affect the HRQOL of middle-aged and older adults.

\section{Materials and Methods}

\subsection{Study Design}

This was a secondary analysis using the 2013-2018 KNHANES as a cross-sectional study to identify the active aging factors that affect the HRQOL in middle-aged and older Koreans.

\subsection{Research Subjects}

This study used the 6-year data, which included a combination of the sixth (2013-2015) and seventh (2016-2018) data, from the KNHANES [22]. The KNHANES is a national surveillance system that has been assessing the health and nutritional status of Koreans since 1998. It is conducted by the Korea Centers for Disease Control and Prevention (KCDC) every 3 years using nationally representative samples of the civilian non-institutionalized Korean population. The sampling plan followed a multi-stage clustered probability design. Health interviews and health examination surveys were conducted. Of the 47,217 survey participants, only 14,117 were included in this study. Participants aged $<55$ years $(n=30,765)$ and those with missing survey data $(n=2335)$ were excluded.

\subsection{Definition of Variables}

2.3.1. Quality of Life

The EuroQol-5 Dimension (EQ-5D) questionnaire developed by the Euro-Qol Group was used in the KNHANES to measure HRQOL. The EQ-5D questionnaire consists of five items: mobility, self-care, usual activities, pain/discomfort, and anxiety/depression. Each dimension is represented by a single item with three levels of responses: no problem, some 
problems, and extreme problems. Each item in the questionnaire is rated as follows: 1 point, no problem or no inconvenience; 2 points, some problems or inconveniences; and 3 points, extreme problems or unable to do anything. The KNHANES used the Korean version of the EQ-5D questionnaire which was already developed and proved its validity and reliability to investigate HRQOL [23,24], and provided the EQ-5D index score. In this study, the value obtained by converting the EQ-5D index score to a perfect score of 100 was used. To check the distribution of the different items in the EQ-5D questionnaire, the response 'no problem or no inconvenience' was changed to 'no problem status', while 'some problems or inconveniences' or 'extreme problem or unable to do anything' was changed to 'problem status'.

\subsubsection{Active Aging}

In this study, five health factors, two participation factors, and four security factors were selected as components of active aging based on the definition of the WHO [7] and previous studies [25].

\section{Health Factor}

Health factors included medical physical health status, functional physical health status, and mental health status. Medical physical health status was defined as the number of chronic diseases $(0,1$, or $\geq 2)$, while functional physical health status was defined as limitation in physical activities (yes or no). The number of chronic diseases referred to the presence of at least one type of cancer, circulatory disease, musculoskeletal disease, endocrine disease, respiratory disease, and digestive system disease. Mental health status was defined based on the level of stress (much or little), subjective health status (good, moderate, or bad), and status of depression (yes or no).

\section{Participation Factor}

Participation factors were defined based on the status of economic activity (yes or no) and household type (1st generation, 2nd generation, or 3rd generation).

\section{Security Factor}

Security factors were defined based on the income level (1st quartile, 2nd quartile, 3 rd quartile, or 4th quartile), type of home ownership (yes or no), status of private health insurance (yes or no), and status of unmet healthcare needs (yes or no).

\subsubsection{General Characteristics}

Demographic characteristics included sex (men or women), age (55-64 years or $\geq 65$ years), education level (elementary school, middle school, high school, or college or higher), and the presence of a spouse (yes or no). The health behavior characteristics included smoking (yes or no), alcohol use (yes or no), physical activity (yes or no), and average sleep duration $(<6,6-8$, or $\geq 9 \mathrm{~h})$.

\subsection{Statistical Analysis}

Since the KNHANES data were obtained through multistage clustered sampling, all data were analyzed after designing a composite sample with a weighted frequency. The general characteristics of the study subjects and the level of HRQOL were presented as frequency, percentage, mean, and standard error were expressed using descriptive statistics. The relationship between the factors of active aging and HRQOL was analyzed using a $t$-test and analysis of variance. Hierarchical multiple regression analysis was performed to identify the active aging factors that affect HRQOL. In Model I, the general characteristics of the subjects, such as sex, age, education level, presence of a spouse, smoking, alcohol use, physical activity, and average sleeping duration were analyzed. In Model II, among the components of active aging, health factors such as number of chronic diseases, limitations in physical activities, the level of stress, subjective health status, and status of depression 
variables were added to Model I. In Model III, among the components of active aging, participation factors such as status of economic activity and household type were added to Model II. Lastly, in Model IV, security factors such as income level, type of home ownership, status of private health insurance, and status of unmet healthcare needs were added to Model III. All statistical analyses were performed using SPSS Statistics version 23 (IBM Corp., Armonk, NY, USA), and the statistical significance level was set to a two-sided test at $p<0.05$.

\subsection{Ethical Considerations}

All individuals who participated in the KNHANES conducted by the KCDC provided informed consent, and the participants' names were anonymized. This study was approved by the Research Ethics Review Committee (P01-202101-21-001).

\section{Results}

\subsection{General Characteristics of the Subjects}

The demographic and health behavior characteristics of the participants are presented in Table 1 . Among the included participants, $45.8 \%$ were men and $54.2 \%$ were women. In terms of age, $51.8 \%$ participants were aged $55-64$ years, while $48.2 \%$ were over 65 years. With regard to education level, $42.5 \%$ were elementary school graduates. $74.7 \%$ participants had a spouse and $25.3 \%$ participants had no spouse. Meanwhile, $14.3 \%$ were smokers, $43.9 \%$ were alcohol drinkers, and $37.2 \%$ participants performed physical activities. In terms of average sleep duration, $18.1 \%$ participants slept less than $6 \mathrm{~h}$, while $9.2 \%$ participants slept more than $9 \mathrm{~h}$.

Table 1. General characteristics of subjects.

\begin{tabular}{cccc}
\hline Variables & Category & $\mathbf{N}$ & \% \\
\hline Sex & Men & 6097 & 45.8 \\
Age (years) & Women & 8020 & 54.2 \\
& $55-64$ & 6168 & 51.8 \\
Education level & $\geq 65$ & 7949 & 48.2 \\
& Elementary & 6486 & 42.5 \\
& Middle school & 2454 & 17.8 \\
& High school & 3213 & 24.4 \\
Spouse & College or higher & 1964 & 15.3 \\
& Yes & 10,402 & 74.7 \\
Smoking & No & 3715 & 25.3 \\
& Yes & 1804 & 14.3 \\
Alcohol use & No & 12,313 & 85.7 \\
& Yes & 5828 & 43.9 \\
Physical activity & No & 8289 & 56.1 \\
Sleep duration(h) & Yes & 5074 & 37.2 \\
& No & 9043 & 62.8 \\
& $<6$ & 2616 & 18.1 \\
& $6-8$ & 10,094 & 72.7 \\
& $\geq 9$ & 1407 & 9.2 \\
\hline
\end{tabular}

\subsection{Health-Related Quality of Life}

Table 2 shows the participants' HRQOL. The average EQ-5D score was $91.04 \pm 0.143$. The proportions of respondents with 'problem status' were 31.9\% for pain/discomfort, $25.7 \%$ for mobility, $14.5 \%$ for usual activities, $13.5 \%$ for anxiety/depression, and $7.2 \%$ for self-care. 
Table 2. Health-related quality of life.

\begin{tabular}{ccc}
\hline Variables & Category & $\mathbf{N}(\%)$ \\
\hline EQ-5D & & $91.04 \pm 0.143^{*}$ \\
Mobility problem & Yes & $3967(25.7)$ \\
& No & $10,150(74.3)$ \\
Self-care problem & Yes & $1130(7.2)$ \\
& No & $12,987(92.8)$ \\
Usual activities problem & Yes & $2243(14.5)$ \\
& No & $11,874(85.5)$ \\
Pain/Discomfort problem & Yes & $4681(31.9)$ \\
Anxiety/Depression problem & No & $9436(68.1)$ \\
& Yes & $2033(13.5)$ \\
& No & $12,084(86.5)$ \\
\hline
\end{tabular}

* EuroQol-5 Dimension (EQ-5D) score; Mean \pm SE (standard error).

\subsection{Health-Related Quality of Life According to the Components of Active Aging}

Table 3 shows the HRQOL according to the components of active aging. The components of active aging were classified into health, participation, and security factors. Among the health factors, older adults with two or more chronic diseases had a lower quality of life score than those without chronic disease $(p<0.001)$. In terms of functional and physical health, older adults with activity limit had a lower quality of life score than those without activity limit $(p<0.001)$. With regard to mental health, older adults with stress, poor subjective health, and depression had a lower quality of life score $(p<0.001)$. In terms of participation factors, older adults who engaged in economic activities and belonged in a second-generation household had a higher quality of life score $(p<0.001)$. In terms of security factors, first quartile income earners, those who did not own a house, those who were not enrolled in private health insurance, and those with unmet healthcare needs had a lower quality of life score $(p<0.001)$.

Table 3. Health-related quality of life according to active aging.

\begin{tabular}{|c|c|c|c|c|}
\hline Variables & Category & EQ-5D * & $\mathbf{F}$ & $p$-Value \\
\hline \multirow[t]{17}{*}{ Health factors } & \multicolumn{4}{|c|}{ Number of chronic diseases } \\
\hline & 0 & $95.12^{c} \pm 0.155$ & \multirow[t]{3}{*}{622.005} & \multirow[t]{3}{*}{$<0.001$} \\
\hline & 1 & $92.26^{\mathrm{b}} \pm 0.160$ & & \\
\hline & $\geq 2$ & $86.83^{a} \pm 0.212$ & & \\
\hline & \multicolumn{4}{|c|}{ Limitation in physical activities } \\
\hline & Yes & $75.38 \pm 0.437$ & \multirow[t]{2}{*}{1893.263} & \multirow[t]{2}{*}{$<0.001$} \\
\hline & No & $93.47 \pm 0.097$ & & \\
\hline & \multicolumn{4}{|c|}{ Level of stress } \\
\hline & Much & $84.98 \pm 0.319$ & \multirow[t]{2}{*}{630.001} & \multirow[t]{2}{*}{$<0.001$} \\
\hline & Little & $92.54 \pm 0.140$ & & \\
\hline & \multicolumn{4}{|c|}{ Subjective health status } \\
\hline & Good & $97.01^{\mathrm{c}} \pm 0.099$ & \multirow[t]{4}{*}{1813.331} & \multirow[t]{3}{*}{$<0.001$} \\
\hline & Bad & $80.50^{\mathrm{a}} \pm 0.273$ & & \\
\hline & Moderate & $93.63^{b} \pm 0.142$ & & \\
\hline & \multicolumn{3}{|c|}{ Depression } & \\
\hline & Yes & $81.91 \pm 0.517$ & \multirow[t]{2}{*}{350.670} & \multirow[t]{2}{*}{$<0.001$} \\
\hline & No & $91.60 \pm 0.141$ & & \\
\hline \multirow{3}{*}{$\begin{array}{l}\text { Participation } \\
\text { factors }\end{array}$} & \multicolumn{4}{|c|}{ Economic activity } \\
\hline & Yes & $94.26 \pm 0.109$ & \multirow[t]{2}{*}{661.200} & \multirow[t]{2}{*}{$<0.001$} \\
\hline & No & $87.93 \pm 0.246$ & & \\
\hline
\end{tabular}


Table 3. Cont.

\begin{tabular}{|c|c|c|c|c|}
\hline Variables & Category & EQ-5D * & $\mathbf{F}$ & $p$-Value \\
\hline \multirow{18}{*}{ Security factors } & \multicolumn{4}{|c|}{ Household type } \\
\hline & 1st generation & $90.25^{\mathrm{a}} \pm 0.223$ & 48.118 & $<0.001$ \\
\hline & 2nd generation & $92.36^{b} \pm 0.131$ & & \\
\hline & 3rd generation & $90.30^{\mathrm{a}} \pm 0.303$ & & \\
\hline & \multicolumn{4}{|c|}{ Income level } \\
\hline & 1st quartile & $85.37^{a} \pm 0.251$ & 631.341 & $<0.001$ \\
\hline & 2nd quartile & $91.59^{b} \pm 0.151$ & & \\
\hline & 3rd quartile & $93.93^{c} \pm 0.107$ & & \\
\hline & 4th quartile & $95.37^{\mathrm{d}} \pm 0.090$ & & \\
\hline & \multicolumn{4}{|c|}{ Home ownership } \\
\hline & Yes & $92.09 \pm 0.157$ & 155.936 & $<0.001$ \\
\hline & No & $87.78 \pm 0.305$ & & \\
\hline & \multicolumn{4}{|c|}{ Private health insurance } \\
\hline & Yes & $93.64 \pm 0.101$ & 646.294 & $<0.001$ \\
\hline & No & $86.75 \pm 0.261$ & & \\
\hline & \multicolumn{4}{|c|}{ Unmet healthcare needs } \\
\hline & Yes & $80.88 \pm 0.321$ & 1569.184 & $<0.001$ \\
\hline & No & $92.29 \pm 0.129$ & & \\
\hline
\end{tabular}

*Values are Mean \pm SE (standard error); Bonferroni correction: $\mathrm{a}<\mathrm{b}<\mathrm{c}<\mathrm{d}$.

\subsection{Active Aging Factors Affecting Health-Related Quality of Life}

Table 4 shows the active aging factors that affect HRQOL. Multiple regression analysis was conducted by hierarchically inputting the general characteristic factors and components of active aging, such as health factors, participation factors, and security factors. As a result, the $\mathrm{R}^{2}$ of demographic characteristics in Model I was $14.0 \%(\mathrm{~F}=207.187, p<0.001)$. HRQOL was higher in men than in women and in older adults who had a spouse than those who didn't have a spouse. The HRQOL was low in participants aged over 65 years, with a low level of education, who were smokers, and with a sleep duration of less than 6 $\mathrm{h}$ or more than $9 \mathrm{~h}$ compared with those with a sleep duration of 6-8 $\mathrm{h}$.

The $\mathrm{R}^{2}$ of Model II was $36.1 \%(\mathrm{~F}=277.398, p<0.01)$, which increased by $22.1 \% p$ after introducing the health factors. HRQOL was lower in participants with two or more chronic diseases, high level of stress, and depression. Moreover, those with activity limits ( $\mathrm{B}=$ $-11.367, p<0.001)$ and those with poor subjective health $(B=-7.888, p<0.001)$ had a significantly lower HRQOL.

The $\mathrm{R}^{2}$ of Model III was $36.4 \%$ ( $\left.\mathrm{F}=271.572, p<0.001\right)$, which increased by $0.3 \% p$ after introducing the participation factors. The HRQOL of older adults who engaged in economic activities was higher than that of older adults who did not engage in economic activities $(\mathrm{B}=1.803, p<0.001)$.

The $\mathrm{R}^{2}$ of Model IV was $38.2 \%(\mathrm{~F}=216.656, p<0.001)$, which increased by $1.8 \% p$ after introducing the security factors. The HRQOL was lower in older adults with the lowest income level (1st quartile) than in those with the highest income level (4th quartile); HRQOL was higher in older adults who owned a house than in those who did not own a house. In addition, the HRQOL was higher in those who had private health insurance than in those who did not have private health insurance $(B=1.075, p<0.001)$. Those who did not meet healthcare needs showed remarkably lower quality of life compared with those who met healthcare needs $(B=-5.518, p<0.001)$.

As a result of comparing the absolute values among variables in Model IV, in which all variables were included, activity limit $(B=-10.477, p<0.001)$ and subjective health status $(B=-7.282, p<0.001)$ had the strongest influence on the HRQOL of middle-aged and older people. 
Table 4. Active aging factors affecting health-related quality of life.

\begin{tabular}{|c|c|c|c|c|c|c|c|c|c|c|c|c|c|}
\hline \multirow{2}{*}{ Variables } & \multirow{2}{*}{ Category } & \multicolumn{3}{|c|}{ Model I* } & \multicolumn{3}{|c|}{ Model II ** } & \multicolumn{3}{|c|}{ Model III *** } & \multicolumn{3}{|c|}{ Model IV **** } \\
\hline & & B & SE & $p$-Value & B & SE & $p$-Value & B & SE & $p$-Value & B & SE & $p$-Value \\
\hline Sex (ref. Women) & Men & 1.486 & 00.332 & $<0.001$ & 0.809 & 0.148 & $<0.001$ & 0.487 & 0.153 & 0.002 & 0.367 & 0.172 & 0.038 \\
\hline Age(years) (ref. 55-64) & $\geq 65$ & -3.557 & 0.203 & $<0.001$ & -2.666 & 0.220 & $<0.001$ & -2.185 & 0.235 & $<0.001$ & -1.763 & 0.212 & $<0.001$ \\
\hline \multirow{3}{*}{ Education (ref. College or higher) } & Elementary & -5.512 & 0.281 & $<0.001$ & -2.573 & 0.253 & $<0.001$ & -2.782 & 0.258 & $<0.001$ & -2.167 & 0.270 & $<0.001$ \\
\hline & Middle school & -2.066 & 0.313 & $<0.001$ & -0.162 & 0.253 & 0.525 & -0.361 & 0.257 & 0.165 & -0.207 & 0.281 & 0.465 \\
\hline & High school & -0.836 & 0.190 & $<0.001$ & 0.099 & 0.145 & 0.500 & 0.032 & 0.148 & 0.831 & 0.104 & 0.155 & 0.506 \\
\hline Spouse (ref. No) & Yes & 3.749 & 0.272 & $<0.001$ & 2.760 & 0.248 & $<0.001$ & 2.768 & 0.248 & $<0.001$ & 1.887 & 0.256 & $<0.001$ \\
\hline Smoking (ref. No) & Yes & -0.886 & 0.301 & 0.005 & -0.234 & 0.252 & 0.359 & -0.215 & 0.252 & 0.398 & 0.099 & 0.234 & 0.674 \\
\hline Physical activity (ref. No) & Yes & 1.941 & 0.196 & $<0.001$ & 1.104 & 0.185 & $<0.001$ & 1.094 & 0.188 & $<0.001$ & 1.088 & 0.196 & $<0.001$ \\
\hline \multirow[t]{2}{*}{ Sleep duration(h) (ref. 6-8 h) } & $<6$ & -2.607 & 0.234 & $<0.001$ & -1.562 & 0.214 & $<0.001$ & -1.513 & 0.202 & $<0.001$ & -1.236 & 0.216 & $<0.001$ \\
\hline & $\geq 9$ & -3.070 & 0.342 & $<0.001$ & -1.492 & 0.298 & $<0.001$ & -1.440 & 0.297 & $<0.001$ & -1.293 & 0.285 & $<0.001$ \\
\hline \multirow[t]{2}{*}{ Number of chronic diseases (ref. 0) } & $\geq 2$ & & & & -1.595 & 0.198 & $<0.001$ & -1.490 & 0.201 & $<0.001$ & -1.572 & 0.194 & $<0.001$ \\
\hline & 1 & & & & -0.110 & 0.152 & 0.471 & -0.058 & 0.154 & 0.709 & -0.108 & 0.163 & 0.512 \\
\hline Limitation in physical activities (ref. No) & Yes & & & & -11.367 & 0.421 & $<0.001$ & -11.140 & 0.411 & $<0.001$ & -10.477 & 0.404 & $<0.001$ \\
\hline Level of stress (ref. Little) & Much & & & & -3.494 & 0.239 & $<0.001$ & -3.635 & 0.239 & $<0.001$ & -3.185 & 0.240 & $<0.001$ \\
\hline \multirow[t]{2}{*}{ Subjective health status (ref. Moderate) } & Good & & & & 1.414 & 0.131 & $<0.001$ & 1.356 & 0.130 & $<0.001$ & 1.206 & 0.135 & $<0.001$ \\
\hline & Bad & & & & -7.888 & 0.214 & $<0.001$ & -7.772 & 0.211 & $<0.001$ & -7.282 & 0.217 & $<0.001$ \\
\hline Economic activity (ref. No) & Yes & & & & & & & 1.803 & 0.189 & $<0.001$ & 1.731 & 0.190 & $<0.001$ \\
\hline \multirow[t]{2}{*}{ Household type (ref. 3rd generation) } & 1st generation & & & & & & & -0.661 & 0.306 & 0.035 & -.0 .072 & 0.295 & 0.808 \\
\hline & $\begin{array}{l}\text { 2nd } \\
\text { generation }\end{array}$ & & & & & & & -0.884 & 0.287 & 0.003 & -0.553 & 0.289 & 0.062 \\
\hline \multirow[t]{3}{*}{ Income level (ref. 4th Quartile) } & 1st Quartile & & & & & & & & & & -1.020 & 0.290 & $<0.001$ \\
\hline & 2nd Quartile & & & & & & & & & & 0.176 & 0.224 & 0.438 \\
\hline & 3rd Quartile & & & & & & & & & & 0.214 & 0.120 & 0.080 \\
\hline Home ownership (ref. No) & Yes & & & & & & & & & & 1.132 & 0.238 & $<0.001$ \\
\hline Private health insurance (ref. No) & Yes & & & & & & & & & & 1.075 & 0.208 & $<0.001$ \\
\hline Unmet healthcare needs (ref. No) & Yes & & & & & & & & & & -5.518 & 0.196 & $<0.001$ \\
\hline$R^{2}$ & & \multicolumn{3}{|c|}{0.140} & \multicolumn{3}{|c|}{0.361} & \multicolumn{3}{|c|}{0.364} & \multicolumn{3}{|c|}{0.382} \\
\hline$\Delta R^{2}$ & & \multirow{2}{*}{\multicolumn{3}{|c|}{$207.187(p<0.001)$}} & \multirow{2}{*}{\multicolumn{3}{|c|}{$\begin{array}{c}0.221 \\
277398(n<0001)\end{array}$}} & \multicolumn{3}{|c|}{0.003} & \multicolumn{3}{|c|}{0.018} \\
\hline$F$ & & & & & & & & \multicolumn{3}{|c|}{$271.572(p<0.001)$} & \multicolumn{3}{|c|}{$216.656(p<0.001)$} \\
\hline
\end{tabular}

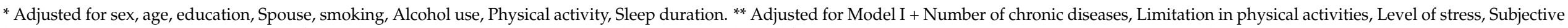
health status, Depression. ${ }^{* * *}$ Adjusted for Model II + Economic activity, Household type. ${ }^{* * * *}$ Adjusted for Model III + Income level, Home ownership, Private health insurance, Unmet healthcare needs. 


\section{Discussion}

The concept of active aging has a limitation. The definitions presented by the international organizations are inconsistent and lack specific indicators and measurements. However, in many countries, it has had a considerable impact on the change of perspectives on old age and the establishment of new strategies [26-28]. In defining the concept of active aging, while the WHO prioritizes the social aspects of health and quality of life, the European Union (EU) and the OECD emphasize the capacity of older adults to contribute to the economy and society with a greater focus on increasing economic productivity during old age [29]. Older people or their families cannot usually solve the problems that they are facing themselves. Hence, these problems must be viewed from a comprehensive perspective of improving the quality of life, not simply expanding economic productivity.

The main result of this study, which was conducted to confirm the relationship between active aging factors and HRQOL in Korean middle-aged and older adults, is that health factors, participation factors, and security factors defined as components of active aging are related to HRQOL. Among them, activity limit and subjective health status which are health factors were closely related with HRQOL.

Older adults are more likely to have difficulty in physical activity as they age. Even in a study of people over 50 years old, those with physical function restrictions had poor physical and mental health conditions and HRQOL [30]. Physical function restrictions can be disadvantageous to access to the social environment and support. To improve the quality of life of older adults, it is necessary to consider the activities that minimize physical function restrictions to determine the factors that need priority. Subjective health status is an important measure for assessing HRQOL and is directly related to quality of life [31]. Subjective health status was a factor affecting quality of life, even for older adults with chronic diseases [32]. Older adults with good physical function showed better subjective health status [33], and those who had more social activities perceived their status more positively [34]. As life expectancy increases, the prevalence of chronic diseases among older adults is also increasing, and chronic diseases are the factors associated with low HRQOL [35]. The most frequent degenerative diseases leading to poor quality of life include cancer, hypertension, osteoporosis, and diabetes [36]. Among them, older adults with arthritis have limited social participation and physical activities compared with those without arthritis, leading to a decrease in quality of life [15]. This finding implies that chronic diseases that worsen physical function restrictions can lower the quality of life. According to the 'National Survey of Older Persons', the average number of chronic diseases among older Korean adults increased from 1.5 cases in 2008 to 2.7 cases in 2017, and the proportion of older adults with three or more chronic diseases increased significantly from $30.7 \%$ to $51.0 \%$. Approximately $8 \%$ of older adults reported that their daily activities were limited [37]. Therefore, early detection and management of chronic diseases that can worsen physical function restrictions in older adults should be recognized as an important factor for improving the HRQOL of the elderly and the establishment of national strategies is desperately needed.

In this study, the HRQOL of older adults who engaged in economic activities was higher than HRQOL of those who did not engage in economic activities $(B=1.732$, $p<0.001)$. Another study using panel data also reported that people engaged in paid work during old age had a high quality of life [38]. However, the quality of life of older adults who engaged in physical labor was lower than that of office workers and was more affected by health factors than that of office workers [39]. Korea has a higher employment rate for older adults than European Union (EU) countries [40], and while the employment rate of the 65- to 69-year-old age group in Korea is higher than that of the OECD average, most of the older adults in Korea finish their core careers in thier early 50s and tend to obtain low-quality and unstable jobs [3]. Employment in old age is an important factor affecting quality of life $[38,41]$. Participation refers to the labor market, employment, education, health, and social policies and programs that support their full participation in the socioeconomic, cultural, and spiritual activities; according to their basic human rights, 
capacities, needs, and preferences, people will continue to make a productive contribution to society in both paid and unpaid activities as they age [7]. For the older adults' economic activities to lead to active aging, various decent jobs must be provided by society.

According to the security meaning of the $\mathrm{WHO}$, when policies and programs address the social, financial, and physical security needs and rights of people as they age, older people are ensured of protection, dignity, and care in the event that they are no longer able to support and protect themselves [7]. We examined the social, financial, and health aspects of individuals and their effects on HRQOL. The HRQOL was low in the group with the lowest income level and with unmet healthcare needs. By contrast, HRQOL was high in the group that owned a house and with private health insurance. It was confirmed not only in this study but also in previous studies $[42,43]$ that high income level and home ownership are obvious factors that positively influence the quality of life of older people.

Unmet healthcare needs are a condition in which medical needs are not met [44]. These are factors that affect disease prognosis in terms of failure to detect disease early, increase in disease severity, and increase in the likelihood of complications [45]; this study also confirmed that unmet healthcare needs have a great influence on HRQOL $(B=-5.518$, $p<0.001)$. Private health insurance, which can also affect HRQOL, is a factor affecting the experience of unmet healthcare needs. In particular, it can greatly affect those who have experienced unmet healthcare needs for economic reasons [46], and older people with underinsurance are more likely to have the experience of unmet healthcare needs than those with adequate insurance $[47,48]$. In terms of the security factors of active aging, national policy efforts such as reducing the rate of unmet healthcare needs, as a significant security factor affecting the quality of life identified in this study, are needed. As we age, security needs and rights should be considered to improve quality.

Due to the rapid aging of the population, the average age of workers in the labor market is predicted to increase. The results of this study imply that it is necessary to understand the three factors constituting active aging and to approach them in multifaceted ways to improve the quality of life of people aged over 55 years.

The strength of this study is that it is highly representative as it uses large-scale data surveyed nationally and is a weighted composite sample analysis. However, this study has several limitations. First, considering that the study included middle-aged and older adults from Korea, the results are not necessarily generalizable to other population groups. Second, the possibility of under-reporting or over-reporting cannot be ruled out because the analysis results were based on the participant's response to the questionnaire survey. Third, the variables used in the analysis of the three factors suggested as active aging factors were about partial aspects of the entire active aging components. For example, since the data on care activities, which is a representative index of the participation factors, were not obtained in the KNHANES, the type of household was used as a proxy indicator. Fourth, this was a cross-sectional study; hence, the causal relationship between active aging factors and HRQOL could not be inferred. Nevertheless, the finding of this study that active aging factors are closely related to the HRQOL of elderly individuals can be used as a basis for further studies. Based on the results of this study, we suggest an additional study to derive the relationship between HRQOL and various indicators that reflect active aging factors.

\section{Conclusions}

This study showed meaningful results regarding the relationship between active aging factors and HRQOL in middle-aged and older Koreans. The health factors, participation factors, and security factors that constitute active aging were related to HRQOL. In particular, among the health factors, subjective health status and activity limit were closely related to HRQOL. Therefore, a multifaceted approach including each factor of active aging is necessary to improve the quality of life of middle-aged and older adults. 
Author Contributions: Conceptualization, H.K. and M.E.; methodology, H.K. and M.E.; software, M.E.; validation, H.K. and M.E.; formal analysis, M.E.; investigation, M.E.; resources, M.E.; data curation, M.E.; writing—original draft preparation, M.E.; writing—review and editing, H.K.; visualization, H.K. and M.E.; supervision, H.K.; project administration, H.K.; funding acquisition, H.K. and M.E. All authors have read and agreed to the published version of the manuscript.

Funding: This research received no external funding.

Institutional Review Board Statement: This study was approved by the Research Ethics Review Committee (P01-202101-21-001).

Informed Consent Statement: Informed consent was obtained from all participants involved in the KNHANES by KCDC.

Data Availability Statement: Restrictions apply to the availability of these data. Data were obtained from KCDC and are available from https:/ / knhanes.cdc.go.kr/knhanes/main.do.

Conflicts of Interest: The authors declare no conflict of interest.

\section{References}

1. United Nations Population Fund (UNFPA). Aging. Available online: https://www.unfpa.org/ageing. (accessed on 14 July 2020).

2. National Statistical Office. World and Korea's Population Outlook and Current Status. Available online: http://kostat.go.kr/ portal / korea / kor_nw/1/1/index.board?bmode=read\&aSeq=377226 (accessed on 14 July 2020).

3. Organization for Economic Co-operation Development (OECD). Working Better with Age: Korea. Available online: https:/ / www.oecd.org/korea/working-better-with-age-korea-9789264208261-en.htm (accessed on 14 July 2020).

4. Park, S. A comparative study of the factors influencing life satisfaction between urban and rural elderly. J. Welf. Aged 2010, 47, 137-160.

5. Bowling, A. Enhancing later life: How older people perceive active ageing? Aging Ment. Health 2008, 12, 293-301. [CrossRef] [PubMed]

6. OECD. Maintaining Prosperity in an Ageing Society; OECD: Paris, France, 1998.

7. World Health Organization. Active Ageing: A Policy Framework; World Health Organization: Geneva, Switzerland, 2002.

8. Conde-Sala, J.L.; Portellano-Ortiz, C.; Calvó-Perxas, L.; Garre-Olmo, J. Quality of life in people aged 65+ in Europe: Associated factors and models of social welfare-analysis of data from the SHARE project (Wave 5). Qual. Life Res. 2017, 26, 1059-1070. [CrossRef] [PubMed]

9. Luo, N.; Johnson, J.A.; Shaw, J.W.; Feeny, D.; Coons, S.J. Self-reported health status of the general adult US population as assessed by the EQ-5D and Health Utilities Index. Med. Care 2005, 43, 1078-1086. [CrossRef]

10. Eaglehouse, Y.L.; Schafer, G.L.; Arena, V.C.; Kramer, M.K.; Miller, R.G.; Kriska, A.M. Impact of a community-based lifestyle intervention program on health-related quality of life. Qual. Life Res. 2016, 25, 1903-1912. [CrossRef]

11. Mountain, G.; Windle, G.; Hind, D.; Walters, S.; Keertharuth, A.; Chatters, R.; Sprange, K.; Craig, C.; Cook, S.; Lee, E. A preventative lifestyle intervention for older adults (lifestyle matters): A randomised controlled trial. Age Ageing 2017, 46, 627-634. [CrossRef] [PubMed]

12. Pan, C.-W.; Cong, X.; Zhou, H.-J.; Li, J.; Sun, H.-P.; Xu, Y.; Wang, P. Self-reported sleep quality, duration, and health-related quality of life in older Chinese: Evidence from a rural town in Suzhou, China. J. Clin. Sleep Med. 2017, 13, 967-974. [CrossRef] [PubMed]

13. Van Wilder, L.; Rammant, E.; Clays, E.; Devleesschauwer, B.; Pauwels, N.; de Smedt, D. A comprehensive Catalogue of EQ-5D scores in chronic disease: Results of a systematic review. Qual. Life Res. 2019, 28, 1-9. [CrossRef]

14. Megari, K. Quality of life in chronic disease patients. Health Psychol. Res. 2013, 1, e27. [CrossRef]

15. Hong, M.; Shin, H.; De Gagne, J.C. Social networks, health-promoting behaviors, and health-related quality of life in older adults with and without arthritis. PLOS ONE 2019, 14, e0220180. [CrossRef]

16. Harada, K.; Masumoto, K.; Katagiri, K.; Fukuzawa, A.; Chogahara, M.; Kondo, N.; Okada, S. Frequency of going outdoors and health-related quality of life among older adults: Examining the moderating role of living alone and employment status. Geriatr. Gerontol. Int. 2018, 18, 640-647. [CrossRef]

17. Kim, J.; Noh, J.W.; Park, J.; Huh, T.; Kwon, Y.D. Association between health-related quality of life and work status in older Korean adults. Geriatr. Gerontol. Int. 2018, 18, 1629-1633. [CrossRef]

18. Yeunhee, K.; Yoonjung, K. Health-related quality of life and mental health of elderly by occupational status. Iran. J. Public Health 2017, 46, 1028.

19. Dajak, L.; Mastilica, M.; Orešković, S.; Vuletić, G. Health-related quality of life and mental health in the process of active and passive ageing. Psychiatr. Danub. 2016, 28, 404-408.

20. Stenner, P.; McFarquhar, T.; Bowling, A. Older people and 'active ageing': Subjective aspects of ageing actively. J. Health Psychol. 2011, 16, 467-477. [CrossRef]

21. Fanta, J. Quality of Life of the Elderly and Applicability of the Active Ageing Index to Latin American Countries. In Building Evidence for Active Ageing Policies; Springer: Berlin/Heidelberg, Germany, 2018; pp. 385-407. 
22. Korea Centers for Disease Control and Prevention. The Statistics on Korean National Health and Nutrition Examination in: Ministry of Health and Welfare. Available online: https:// knhanes.cdc.go.kr/knhanes/main.do (accessed on 20 June 2020).

23. Kim, M.-H.; Cho, Y.-S.; Uhm, W.-S.; Kim, S.; Bae, S.-C. Cross-cultural adaptation and validation of the Korean version of the EQ-5D in patients with rheumatic diseases. Qual. Life Res. 2005, 14, 1401-1406. [CrossRef]

24. Lee, Y.-K.; Nam, H.-S.; Chuang, L.-H.; Kim, K.-Y.; Yang, H.-K.; Kwon, I.-S.; Kind, P.; Kweon, S.-S.; Kim, Y.-T. South Korean time trade-off values for EQ-5D health states: Modeling with observed values for 101 health states. Value Health 2009, 12, 1187-1193. [CrossRef] [PubMed]

25. Thanakwang, K.; Soonthorndhada, K. At trib utes of Ac tive Age ing among Older Per sons in Thai land: Evidence from the 2002 Survey. Ed. Advis Board 2006, 21, 113.

26. Walker, A.; Maltby, T. Active ageing: A strategic policy solution to demographic ageing in the European Union. Int. J. Soc. Welf. 2012, 21, S117-S130. [CrossRef]

27. Foster, L.; Walker, A. Gender and active ageing in Europe. Eur. J. Ageing 2013, 10, 3-10. [CrossRef] [PubMed]

28. Walker, A. A strategy for active ageing. Int. Soc. Secur. Rev. 2002, 55, 121-139. [CrossRef]

29. Kim, K.; Kim, S. Multi-dimensional measuring and multi-level analysis of active ageing in 16 OECD countries. Soc. Welf. Pol. 2014, 41, 1-32.

30. Thompson, W.W.; Zack, M.M.; Krahn, G.L.; Andresen, E.M.; Barile, J.P. Health-related quality of life among older adults with and without functional limitations. Am. J. Public Health 2012, 102, 496-502. [CrossRef]

31. Maniscalco, L.; Miceli, S.; Bono, F.; Matranga, D. Self-Perceived Health, Objective Health, and Quality of Life among People Aged 50 and Over: Interrelationship among Health Indicators in Italy, Spain, and Greece. Int. J. Environ. Res. Public Health 2020, 17, 2414. [CrossRef] [PubMed]

32. Ju, S.; Kim, K.-S. The relationship among quality of life, depression and subjective health status of the elderly with chronic disease in Korea. Indian J. Sci. Technol. 2015, 8, 1-8. [CrossRef]

33. Sposito, G.; Diogo, M.; Fernanda, A.; Neri, A.L.; Guariento, M.E.; De Sousa, M.L. Relationship Between Subjective Well-being And The Functionality Of Elderly Outpatients [relações Entre O Bem-estar Subjetivo E A Funcionalidade Em Idosos Em Seguimento Ambulatorial]. Rev. Bras. De Fisioter. 2010, 14, 81-89. [CrossRef]

34. Gilmour, H. Social participation and the health and well-being of Canadian seniors. Health Rep. 2012, 23, 23-32. [PubMed]

35. Puteh, S.E.W.; Siwar, C.; Zaidi, M.A.S.; Kadir, H.A. Health related quality of life (HRQOL) among low socioeconomic population in Malaysia. BMC Public Health 2019, 19, 551.

36. Li, C.; Ford, E.S.; Zhao, G.; Mokdad, A.H. Associations of health risk factors and chronic illnesses with life dissatisfaction among US adults: The Behavioral Risk Factor Surveillance System, 2006. Prev. Med. 2009, 49, 253-259. [CrossRef] [PubMed]

37. Korea Institute for Health and Social Affairs (KIHASA). 2017 National Survey of Older Koreans: Findings and Implications. Available online: https: / www.kihasa.re.kr/web/publication/newbooks_pdsissue/view.do?menuId=46\&tid=71\&bid=200\& ano=1487 (accessed on 20 July 2020).

38. di Gessa, G.; Corna, L.; Price, D.; Glaser, K. The decision to work after state pension age and how it affects quality of life: Evidence from a 6-year English panel study. Age Ageing 2018, 47, 450-457. [CrossRef]

39. Soltysik, B.K.; Kroc, L.; Piglowska, M.; Guligowska, A.; Smigielski, J.; Kostka, T. An evaluation of the work and life conditions and the quality of life in 60 to 65 year-old White-Collar employees, manual workers, and unemployed controls. J. Occup. Environ. Med. 2017, 59, 461-466. [CrossRef] [PubMed]

40. Um, J.; Zaidi, A.; Choi, S.J. Active Ageing Index in Korea-comparison with China and EU countries. Asian Soc. Work Policy Rev. 2019, 13, 87-99. [CrossRef]

41. Van Minh, H.; Byass, P.; Thi Kim Chuc, N.; Wall, S. Patterns of health status and quality of life among older people in rural Viet Nam. Glob. Health Action 2010, 3, 2124. [CrossRef]

42. Huguet, N.; Kaplan, M.S.; Feeny, D. Socioeconomic status and health-related quality of life among elderly people: Results from the Joint Canada/United States Survey of Health. Soc. Sci. Med. 2008, 66, 803-810. [CrossRef] [PubMed]

43. Zumbro, T. The relationship between homeownership and life satisfaction in Germany. Hous. Stud. 2014, 29, 319-338. [CrossRef]

44. Donabedian, A. Aspects of Medical Care Administration: Specifying Requirements for Health Care; Harvard University Press: Cambridge, MA, USA, 1973.

45. Aday, L.A.; Andersen, R. A framework for the study of access to medical care. Health Serv. Res. 1974, 9, 208.

46. Han, J.W.; Kim, D.J.; Min, I.S.; Hahm, M.-I. Association of Supplementary Private Health Insurance Type with Unmet Health Care Needs. Health Policy Manag. 2019, 29, 184-194.

47. Kogan, M.D.; Newacheck, P.W.; Blumberg, S.J.; Ghandour, R.M.; Singh, G.K.; Strickland, B.B.; van Dyck, P.C. Underinsurance among children in the United States. N. Engl. J. Med. 2010, 363, 841-851. [CrossRef] [PubMed]

48. Lavarreda, S.A.; Brown, E.R.; Bolduc, C.D. Underinsurance in the United States: An interaction of costs to consumers, benefit design, and access to care. Annu. Rev. Public Health 2011, 32, 471-482. [CrossRef] 